\title{
The Size of the Sanction Should Depend on the Weight of the Evidence
}

Lando, Henrik

Document Version

Final published version

Publication date:

2004

License

CC BY-NC-ND

Citation for published version (APA):

Lando, H. (2004). The Size of the Sanction Should Depend on the Weight of the Evidence.

Link to publication in CBS Research Portal

\section{General rights}

Copyright and moral rights for the publications made accessible in the public portal are retained by the authors and/or other copyright owners and it is a condition of accessing publications that users recognise and abide by the legal requirements associated with these rights.

\section{Take down policy}

If you believe that this document breaches copyright please contact us (research.lib@cbs.dk) providing details, and we will remove access to the work immediately and investigate your claim. 


\section{LEFIC}

Copenhagen Business School

\section{Center for Law, Economics and Financial Institutions at CBS}

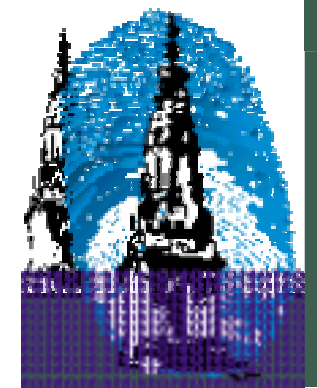

LEFIC WORKING PAPER 2004-08

The Size of the Sanction Should Depend on the Weight of the Evidence

Henrik Lando

www.cbs.dk/LEFIC 


\title{
The Size of the Sanction Should Depend on the Weight of the Evidence
}

\author{
Henrik Lando, \\ IVS, Copenhagen Business School, \\ e-mail: hl.ivs@cbs.dk
}

August 3, 2004

\begin{abstract}
The paper argues that society should vary the sanction applied to a criminal defendant with the weight of the evidence against him or her. This is optimal when it is costly for society to apply sanctions, since it can yield the same degree of deterrence while requiring fewer resources to be spent on sanctioning. Furthermore, when the unfairness of convicting an innocent defendant increases with the size of the sanction, this provides a further rationale for graduating sanctions with the probability of guilt.

Some objections are briefly discussed, mainly that it is inherently unfair to apply different sanctions on people, who have committed the same offense, and that the legal system will lose legitimacy if it allows sanctions to vary in the way suggested.
\end{abstract}




\section{Introduction}

Imagine a criminal trial in which the jury has found the defendant guilty, but where doubts concerning guilt remain. It may for example be difficult to exlude the possibility that the defendant acted, or believed that he or she acted, in self-defense. Should, then, the existence and the extent of the remaining doubt influence the size of the sanction? In the present system, it is generally maintained that guilt must be proven 'beyond a reasonable doubt', and that once this level of certainty has been attained, the sanction should not depend on the extent of any remaining uncertainties. The question raised in this article is whether this system is socially optimal, or whether the sanction should be allowed to vary with the extent of remaining doubts or, put differently, with the certainty of guilt.

In attempting to answer this question, the first part of the article establishes a sufficient condition for it to be optimal to vary the sanction with the degree of certainty. It will be shown to be sufficient that the cost to society of imposing a sanction increases with its size. This condition will generally be fulfilled, at least for non-monetary sanctions ${ }^{1}$. To see why this is sufficient, note that a sanction applied to an innocent defendant does not have a deterrent effect on potential offenders ex-ante, since the sanction is not applied to an offender ${ }^{2}$. Therefore, when the defendant's guilt is more certain, the probability that any given sanction will be 'wasted' on an innocent person is smaller, and a higher sanction therefore yields more deterrence per sanctioning cost (e.g. per year of imprisonment).

The second part of the article demonstrates that including fairness as a social concern provides a further rationale for varying sanctions with the probability of guilt. There are two countervailing forces. On the one hand, sanctioning an innocent defendant is not only a waste in terms of its effect on deterrence, but also unfair to the defendant, and more unfair the greater the sanction. This is an argument for varying sanctions. On the other hand, if considerations of fairness call for a given level of punishment (as the 'correct' or 'fair' level), this provides a rationale for not varying sanctions. Of these two forces, it will be shown that

\footnotetext{
${ }^{1}$ A fine can to some extent be viewed as simply a transfer.

${ }^{2}$ This argument presupposes that potential offenders understand that some of the convicted are innocent, for if potential offenders think that all convicted are guilty, the deterrent effect will be the same whether the convicted is innocent or guilty.
} 
the former wins out ${ }^{3}$, and that considerations of fairness therefore overall provide a rationale for varying sanctions with the weight of the evidence.

These points are developed in the model, after which some objections will be discussed, mainly that it is inherently unfair to apply different sanctions to people, who have committed the same offense, and that the legal system will lose legitimacy if it admits that it bases its verdicts on probabilistic evidence rather than on certainty and 'proof'. Implications for legal practice will also be briefly discussed. The article ends with a short literature review, and a summary.

\section{The Model}

The model is in the tradition of Becker [2], and builds more particularly on Shavell and Polinsky [6]. The Shavell and Polinsky article, however, abstracts from uncertainty concerning guilt, and hence does not address the issue of unfair conviction and its unfairness cost. The present model extends their framework in this dimension.

Assume only one kind of criminal act, that causes harm, $h$, to society. Potential criminals are assumed risk neutral, and will commit the crime if the benefit, $v$, is greater than the expected sanction. The total population is normalized to one, and the fraction of the population with benefit $v$ is given by the density function $z(v)>0$, and the cumulative distribution function $Z(v)$. It will be assumed that whenever the criminal act has been committed, somebody will report it to the police, who will investigate and press charges if there is sufficient evidence against a prime suspect. The evidence generated through investigations and court proceedings will be stochastic, and may be more or less incriminating. It will be assumed that the judge/jurors can rank the evidence in this respect, and that the ranking can be expressed by a continuous variable $x \in[0, \infty[$, where the number is higher the more conclusive the evidence against the prime suspect.

The ratio of the probability of the prime suspect's guilt (where guilt will be represented by $g$ ), and his or her innocence $(i)$, can be found from the Bayesian formula $P=A \times L$, where $P$ is the ex-post ratio of the probability of guilt to the probability of innocence, $A$ is the same ratio ex-ante, where ex-ante refers to the information existing before any evidence is presented, and $L$ is the likelihood ratio:

$$
L=\frac{\text { the probability of observing the evidence given guilt }}{\text { the probability of observing the evidence given innocence }}
$$

\footnotetext{
${ }^{3}$ When the social welfare derived from applying the fair sanction can be assumed to be differentiable in the size of the sanction.
} 
Let $f_{g}(x)$ express the probability of $x$ forthcoming against the prime suspect, if it is assumed that the prime suspect did commit the crime, and $f_{i}(x)$ the probability of $x$ forthcoming against the prime suspect, if it is assumed that someone other than the prime suspect committed the crime. The probability of guilt given $x$ can then be written ${ }^{4}$ :

$$
\operatorname{prob}(g \mid x)=\frac{f_{g}(x)}{f_{g}(x)+f_{i}(x)}
$$

since $\operatorname{prob}(g \mid x)+\operatorname{prob}(i \mid x)=1$, which follows from the fact that the prime suspect is either guilty or innocent. Note that since the evidence is ordered in such a way that a higher $x$ means a higher probability of guilt, the likelihood ratio $\frac{f_{g}(x)}{f_{i}(x)}$ is by definition increasing in $x$ (since the likelihood ratio is nearly identical to the probability of guilt in the present context).

If the sanction is $s(x)$ and the level of utility for which a person will be exactly deterred is $\widetilde{v}$, then

$$
\widetilde{v}=\int_{0}^{\infty} s(x) f_{g}(x) d x
$$

$Z(\widetilde{v})$ is then the law-abiding and $1-Z(\widetilde{v})$ the criminal part of the population. For reasons to which we will return, it is natural to imagine policies, where $s(x)$ is zero for low values of $x$, and only increasing thereafter, but the analysis will be not be restricted to such policies.

We now address whether sanctions should be varied when society only cares about achieving deterrence at low sanctioning costs. Subsequently, the consequences of adding fairness considerations will be analyzed.

\section{The Case of Costly Sanctions Without Concern for Fairness}

It will now be assumed that the cost, $c$, of sanctioning a defendant, whether guilty or innocent, depends on the size of the sanction, which again may depend on the level of certainty concerning guilt, i.e.: $c=c(s(x))$. Note that when sanctioning is costly, Becker's result [2] that maximal penalties are optimal (because the maximal penalty economizes on enforcement effort) does not apply.

\footnotetext{
${ }^{4}$ This follows from Bayes' formula. The derivation can be found in Lando [3]. In that paper, $x$ is treated as the marginal evidence beyond the level that creates a probability higher than $1 / 2$. The present notation is simpler, $x$ is here the total evidence.
} 
The cost of sanctioning may include the loss of utility of the convicted as well as the cost to society of incarcerating an individual, but as mentioned it does not include the sense of unfairness, which an unfairly convicted individual is likely to feel (or which others may feel on his or her behalf).

Social welfare is maximized when total social costs $S C$ are minimized with respect to $s(x)$. $S C$ can be written ${ }^{5}$ :

$$
S C=(1-Z(\widetilde{v}))\left[h+\int_{0}^{\infty}\left(f_{g}(x)+f_{i}(x)\right) c(s(x)) d x\right]
$$

where

$$
\widetilde{v}=\int_{0}^{\infty} s(x) f_{g}(x) d x
$$

The following proposition can now be proven:

Proposition: When sanctions are costly and not just a transfer, a constant sanction is dominated in terms of social welfare by a sanction that increases with $x$.

Proof: Take an interval $I=\left[x_{0} ; x_{2}\right]$, in which a constant sanction, $s$, is applied. An increasing sanction, $\widetilde{s}$, that dominates $s$ can be formed as follows: Split the interval into two: $\left[x_{0} ; x_{1}\right]$ and $\left[x_{1} ; x_{2}\right]$, such that $\int_{x_{0}}^{x_{1}} f_{g}(x) d x=\int_{x_{1}}^{x_{2}} f_{g}(x) d x$. Let the sanction in the first interval be $s-\Delta s$ and in the latter interval $s+\Delta s$ where $\Delta s$ is some small number. This sanction increases stepwise with $x$. The total expected sanction when $\widetilde{s}$ is applied is the same as when $s$ is applied in the whole interval since

$$
(s-\Delta s) \int_{x_{0}}^{x_{1}} f_{g}(x) d x+(s+\Delta s) \int_{x_{1}}^{x_{2}} f_{g}(x) d x=s \int_{x_{0}}^{x_{2}} f_{g}(x) d x .
$$

when $\int_{x_{0}}^{x_{1}} f_{g}(x) d x=\int_{x_{1}}^{x_{2}} f_{g}(x) d x$. Thus, deterrence is unchanged. This means that the number of crimes is unchanged, and what counts for social welfare is whether or not the cost of sanctioning will increase or decrease. Given the policy $\widetilde{s}$, the

\footnotetext{
${ }^{5}$ It is assumed here that the crime is of the kind where the utility derived by the offender would be considered to be 'socially illicit' by most people, and so should not be included in the social welfare function. However, whether or not the utility of the offender is included plays no important role in what follows.
} 
cost of sanctioning in the interval $\left[x_{0} ; x_{1}\right]$ will be lowered by the amount

$$
(c(s)-c(s-\Delta s)) \int_{x_{0}}^{x_{1}}\left(f_{g}(x)+f_{i}(x)\right) d x
$$

since the number of convicted defendants, who did commit the crime, will be $\int_{x_{0}}^{x_{1}} f_{g}(x) d x$, while the number of innocently convicted defendants in the interval will be $\int_{x_{0}}^{x_{1}} f_{i}(x) d x$. The cost of sanctioning in the interval $\left[x_{1} ; x_{2}\right]$ will, by the same reasoning, be increased by the amount $(c(s+\Delta s)-c(s)) \int_{x_{1}}^{x_{2}}\left(f_{g}(x)+\right.$ $\left.f_{i}(x)\right) d x$. For a small $\Delta s$, the net increase in sanctioning cost can be approximated as $c^{\prime}(s) \Delta s\left(\int_{x_{1}}^{x_{2}}\left(f_{g}(x)+f_{i}(x)\right) d x-\int_{x_{0}}^{x_{1}}\left(f_{g}(x)+f_{i}(x)\right) d x\right)=c^{\prime}(s) \Delta s\left(\int_{x_{1}}^{x_{2}} f_{i}(x)\right) d x-$ $\left.\left.\int_{x_{0}}^{x_{1}} f_{i}(x)\right) d x\right)$, where the latter equation follows from the fact that $\int_{x_{0}}^{x_{1}} f_{g}(x) d x=$ $\int_{x_{1}}^{x_{2}} f_{g}(x) d x$. This net increase is negative, since $c^{\prime}(s)>0$ and since $\left.\int_{x_{1}}^{x_{2}} f_{i}(x)\right) d x-$ $\left.\int_{x_{0}}^{x_{1}} f_{i}(x)\right) d x<0$. The latter follows from the assumption that $f_{g} / f_{i}$ is increasing in $x$, and from the equation $\int_{x_{0}}^{x_{1}} f_{g}(x) d x=\int_{x_{1}}^{x_{2}} f_{g}(x) d x$. To see this, note that when $f_{g} / f_{i}$ is increasing in $x$, there must be some constant $\kappa_{1}$ where $f_{g}(x) / f_{i}(x)<\kappa_{1}$ in the interval $\left[x_{0} ; x_{1}\right]$ and $f_{g}(x) / f_{i}(x)>\kappa_{1}$ in the interval $\left[x_{1} ; x_{2}\right]$. This means that $\int_{x_{0}}^{x_{1}} \kappa_{1} f_{i}(x) d x>\int_{x_{0}}^{x_{1}} f_{g}(x) d x=\int_{x_{1}}^{x_{2}} f_{g}(x) d x>\int_{x_{1}}^{x_{2}} \kappa_{1} f_{i}(x) d x$, hence $\int_{x_{0}}^{x_{1}} f_{i}(x) d x>$ $\int_{x_{1}}^{x_{2}} f_{i}(x) d x$. Since the new stepwise increasing sanctioning policy yields the same level of deterrence and spends fewer resources on sanctioning, society should prefer it. $Q E D$.

The point is simply that sanctions deter more when applied to the guilty than when applied to the innocent. As a consequence, a higher sanction may be justified when it is highly certain that the defendant is guilty, but may be unjustified, when there is less certainty. To illustrate this point, consider a potential offender, who contemplates the possible outcomes if he or she commits the crime, and assume, to demonstrate the forces at work, that he or she contemplates two different courtproceedings (each of which may either involve him or herself or an innocently accused person): in one proceeding the evidence amounts to $99 \%$ certainty (e.g. 
because DNA evidence can be used), and in the other, the evidence amounts to $90 \%$ certainty of guilt (e.g. because witness testimony is the only evidence). When the former (latter) proceeding occurs the probability that it involves the offender is $99 \%(90 \%)$. If the sanction in both proceedings is three years imprisonment ${ }^{6}$, and the two proceedings occur with the same probability of $20 \%$, the potential offender can calculate the expected sanction to be

$$
0.2 \times \frac{9}{10} \times 3+0.2 \times \frac{99}{100} \times 3=1.13
$$

from the two kinds of proceedings, if he or she commits the crime. If, instead, the sanction is five years in one proceeding and one year in the other, the expected sanction will be

$$
0.2 \times \frac{9}{10} \times 1+\frac{99}{100} \times 0.2 \times 5=1.17
$$

In this example, the expected sanction is approximately $3 \%$ higher when sanctions are varied, while sanctioning costs are identical.

This raises two issues. First, the main argument presupposes, as mentioned, that potential offenders realize that the sanction may be applied to an innocent person, i.e. it is assumed that the policy pursued by the courts is reflected (to some extent at least) in the expectations of potential offenders ${ }^{7}$. Second, it has been implicitly assumed that convicting the innocent does not have a negative impact on deterrence. This assumption is discussed at length in Lando [3]; the argument is that if a person decides not to commit a crime such as murder, assault or theft, the likelihood of that person being innocently convicted for the specific crime is non-existent, since if the person does not commit the crime, there will be no victim and no trial. The potential offender may be innocently convicted of other crimes, but this risk exists whether he or she commits the crime in question or not $^{8}$. Wrong convictions will only lower deterrence when one risks being accused of a specific violation one has not committed, such as speeding in traffic.

\section{The Case Where Fairness Is a Concern}

\footnotetext{
${ }^{6}$ This assumes that the standard of proof is less than $90 \%$, which seems realistic for some kinds of offenses. This is not critical to the argument, however.

${ }^{7}$ If incapacitation is added to the model, no such assumption needs to be made, since then it will automatically be more productive to sanction the guilty than to sanction the innocent.

${ }^{8}$ It may be that sanctions do not enter additively into the utililty function of the defendant, in which case the general possibility of innocent conviction may lower deterence, i.e. the potential offender may think: if one may have to go to prison anyway, why not commit a crime?
} 
The policy of graduating sanctions is further warranted when fairness is a social concern. Fairness considerations may play a role in two senses. In one sense, fairness implies that the sanction should not be applied to innocent defendants, and naturally, in this sense, fairness would call for varying sanctions with the degree of certainty concerning guilt. In another sense, the sanction should be in proportion to the harm caused by the crime or to the malicious intent, or to some other aspect of the crime committed. In this sense, fairness would generally call for a uniform sanction - the correct level of punishment for the given criminal act. It will now be shown that when both these senses of fairness are taken into account, the overall effect is for graduated sanctions.

In the first sense, the cost of sanctioning the innocent will be expressed by the function $\theta(s)$ and may include not only $c(s)$ and the convicted but innocent defendant's sense of unfairness, but also society's dislike for sanctioning unfairly, based on sympathy with the innocent defendant who has been wrongly convicted. In the second sense, the benefit of sanctioning the guilty can be expressed as a function $Q(s) . c(s)$ may be incorporated in $Q(s)$ in which case the benefit $Q(s)$ may be negative, if the cost of sanctioning is higher than the fairness benefit. The fairness benefit may be increasing in $s$, when $s$ is at a low level, and decreasing in $s$, when $s$ is at a high level, as noted by Polinsky and Shavell [6].

The social fairness cost of applying $s(x)$ is $(1-Z(\widetilde{v})) \int \theta(s(x)) f_{i}(x) d x$ cost while the benefit is $(1-Z(\widetilde{v})) \int Q(s(x)) f_{g}(x) d x$, where $(1-Z(\widetilde{v}))$ is the number of crimes, $f_{i}(x)$ is the probability of observing $x$ given that the prime suspect is innocent, and $f_{g}(x)$ is the probability of observing $x$ given that the prime suspect is guilty. The social cost from applying the policy $s(x)$ overall can then be expressed as:

$$
S C=(1-Z(\widetilde{v}))\left[h+\int_{0}^{\infty} \theta(s(x)) f_{i}(x) d x-\int_{0}^{\infty}\left(f_{g}(x) Q(s(x)) d x\right]\right.
$$

where

$$
\widetilde{v}=\int_{0}^{\infty} s(x) f_{g}(x) d x
$$

Proposition: When fairness plays a role both in the sense that the sanction should fit the crime, and in the sense that society perceives an unfairness cost of sanctioning the innocent, a constant sanction is dominated in terms of social welfare by one that increases with $x$.

The proof follows the exact same ideas as that above, and is hence relegated to the appendix. 
The idea of this proof can be illustrated in the example given above. If the sanction for the given offense is three years, and, say, four years is considered the fair sanction by most people (or four years is the median preference), sanctioning defendants who are believed to be guilty with $99 \%$ certainty to five years imprisonment, and those whose guilt is only $90 \%$ certain to one year, would entail a loss in terms of going both beyond and below the fair sanction (assuming that the defendant is guilty), rather than being consistently below the fair sanction. For small graduations around three years, e.g. imposing three and a half year for the former group and two and half years for the latter, the extra cost in terms of not sanctioning the guilty at the correct level is likely to be low, since the effect of increasing the sanction tends to cancel the effect of decreasing it (at least when preferences are differentiable). On the other hand, if the cost of sanctioning an innocent person is one unit per year of imprisonment, graduating the sanctions in the way suggested incurs a total expected cost in terms of this kind of unfairness of $0.01 \times 5+0.1 \times 1=.15$ rather than $0.01 \times 3+0.1 \times 3=.33$. In this example, the unfairness cost is more than halved when sanctions are graduated.

Summing up, there are two main motives for graduating sanctions with the degree of certainty concerning guilt. The first is that sanctioning the innocent is a waste in terms of deterrence, while the other is that sanctioning the innocent is unfair.

\section{Discussion}

Three objections, and implications for legal practice, will now briefly be taken up.

First, it may be viewed as unfair to apply different sanctions to people, who have in fact committed the same offense. Second, it may be argued that the legal system will lose legitimacy, if it admits that sanctions are based on probabilistic evidence rather than on certainty ('proof'), and third, one can argue that criminal sanctions serve as a social stigma, and for this to work, it must be clear to people what they can infer from a verdict.

The first objection loses some of its appeal when it is realized that people may already be sanctioned differently for the same offense. For example, some are acquitted altogether while others receive a harsh penalty for identical offenses, and it is not obvious that this is more fair than a system of graduated sanctions.

Concerning the second objection, legitimacy may perhaps depend on the public understanding that the convicted are (as good as) certain to be guilty. Legitimacy is enhanced thereby, because it gives the impression that the system is able to 
discover the truth (and that the system is dedicated to finding the truth and does not sanction people in a superficial manner). It may perhaps also be argued that the present system, where defendants are acquitted unless proven guilty beyond a certain high threshold of certainty, acts an incentive for the prosecutor to actually discover 'the truth'. However, the real importance of these concerns for legitimacy and incentives are important in reality, and the implications of these constraints if they exist need to be given a thorough investigation. However, note that many people would agree that the death penalty should only be applied (if at all) when the certainty of guilt is very high, which indicates that at least people who hold this opinion realize that not all sanctions - not even long prison sentences- are based on complete certainty.

The third objection seems to call for some treshold probability of guilt as a condition for applying a sanction at all, but the objection does not seem to refute the idea that it may be worth sanctioning a person more who is guilty with $99 \%$ certainty than a person who is guilty with $95 \%$ or $90 \%$ certainty. This point is worth elaborating. The analysis has provided reasons for graduating sanctions, but this does not mean that sanctions should vary continuously with the evidence in the sense that a very low probability of guilt should lead to a very low sanction. A threshold of evidence below which a defendant is acquitted is likely to be optimal, if for no other reason because a trial is costly and will not be worth its cost, if the sanction is very low.

On the issue of the implications for legal practice of the present analysis, there are two different views.

One is that the present system already graduates sanctions to some extent ${ }^{9}$. It does, for example, seem likely that a judge or a jury may in some cases be more reluctant to impose a very harsh sanction (such as capital punishment) on a person whose guilt is subject to remaining doubts than on a person whose guilt can be established with high certainty, e.g. through DNA evidence. Furthermore, it may well be that this practice is not stated openly for fear that doing so would undermine legitimacy.

The other view is that sanctions are as a rule not affected by the degree of uncertainty in current practice, and that such a policy would have profound effects on the system. For example, the procedure of first establishing guilt and then determining the sanction may be due for revision, if the size of the sanction becomes connected to the weight of the evidence. This issue is also left for future

\footnotetext{
${ }^{9}$ One judge vehemently denied this in private conversation while another thought that sanctions sometimes depend on the degree of certainty.
} 
research.

\section{The Literature}

The general idea that sanctions should depend on certainty of guilt has not (to my knowledge) been addressed directly in the literature. The following literature is related:

Shavell [8] shows that liability in tort cases should, for optimal internalization of harm, be proportional to the probability of causation. Shavell's model can be exemplified by a polluting factory which can be attributed in a probabilistic sense to forty out of one hundred deaths from lung cancer in a given neighborhood but not to any single individual's death. Shavell's result that the factory should (in the absence of certain administrative concerns) be held liable for $40 \%$ of the compensation for each individual's death, hinges on the observation that this rule provides a correct internalization of the harm incurred by the pollution. In contrast, in the model of this paper, harm was certain to occur, and the reason for graduating sanctions was either to save on sanctioning costs or on unfairness costs, not to equate the expected sanction with the expected harm. The two approaches describe two different situations: one where the effect of an action can be measured only incaccurately and the other where the identity of the wrongdoer cannot be determined with certainty. Still, the results are related and complementary.

Andreoni [1] explains why higher sanctions may lower deterrence: the jury may want to acquit when the sanction is harsh, for fear of sanctioning an innocent person harshly. Andreoni assumes that the sanction is given and cannot be varied with the amount of evidence, but it is clear that varying the sanction would be optimal in this setting.

Schauer and Zeckhauser [7] argue that standards of proof, as applied in diverse domains of decision-making throughout society, should depend on the sanction that follows from an adverse decision. If the sanction is ten years in prison, the standard of proof should be higher than if the sanction is being fired from a job. Although related, this point is different from the points made in the present article: Schauer and Zeckhauser argue that the standard of proof should vary with the sanction; this paper argues the converse, that the sanction should generally depend on the degree of certainty concerning guilt.

\section{Conclusion}

This paper has shown that, under weak conditions, it is optimal to vary sanctions with the degree of certainty concerning guilt. While it is likely to be optimal, 
for reasons that were mentioned but not fully analyzed, not to sanction at all when the probability of guilt is below a certain threshold, the point is that beyond this threshold, it will increase both deterrence and fairness to graduate sanctions. Arguably, sanctions are already graduated to some degree in reality, when judges and jurors are apprehensive about sanctioning an innocent person harshly. However, the conventional view is that they should not do so, and it is likely that they feel constrained in doing so, whereas the present analysis suggests that it should be the general policy.

\section{Appendix}

Proof:

As in the proof of the first proposition, take some interval $I=\left[x_{0} ; x_{2}\right]$, in which for all $x$ in the interval a constant sanction, $s$, is applied. An increasing sanction, $\widetilde{s}$, that dominates $s$ can be formed as follows: Split the interval into two: $\left[x_{0} ; x_{1}\right]$ and $\left[x_{1} ; x_{2}\right]$, such that $\int_{x_{0}}^{x_{1}} f_{g}(x) d x=\int_{x_{1}}^{x_{2}} f_{g}(x) d x$. Let the sanction in the first interval be $s-\Delta s$ and in the latter interval $s+\Delta s$, where $\Delta s$ is some small number. This sanction increases with $x$, stepwise. The total expected sanction when $\widetilde{s}$ is applied is the same as when $s$ is applied in the whole interval, since

$$
(s-\Delta s) \int_{x_{0}}^{x_{1}} f_{g}(x) d x+(s+\Delta s) \int_{x_{1}}^{x_{2}} f_{g}(x) d x=s \int_{x_{0}}^{x_{2}} f_{g}(x) d x .
$$

using that $\int_{x_{0}}^{x_{1}} f_{g}(x) d x=\int_{x_{1}}^{x_{2}} f_{g}(x) d x$. Thus, deterrence is unchanged. This means that only the fairness costs $\theta(s)$ and $Q(s)$ are changed. Given the policy $\widetilde{s}$, the benefit from sanctioning in the interval $\left[x_{0} ; x_{2}\right]$ equals $Q(s-\Delta s) \int_{x_{0}}^{x_{1}} f_{g}(x) d x+$ $Q(s+\Delta s) \int_{x_{1}}^{x_{2}} f_{g}(x) d x$, while the cost from wrong convictions equals $\theta(s-\Delta s)$ $\int_{x_{0}}^{x_{1}} f_{i}(x) d x+\theta(s+\Delta s) \int_{x_{1}}^{x_{2}} f_{i}(x) d x$. The change in social fairness benefit per $\Delta s$ : $\frac{\partial s c}{\partial \Delta s}$ converges to zero when $\Delta s$ converges to zero, if $Q(s)$ is differentiable, as in the first proof.

The unfairness cost of the stepwise policy is $\int_{x_{0}}^{x_{1}} f_{i}(x)\left(\theta(s-\Delta s) d x+\int_{x_{1}}^{x_{2}} f_{i}(x)(\theta(s+\right.$ $\Delta s) d x$ while under the constant sanction, it was $\int_{x_{0}}^{x_{1}} f_{i}(x)(\theta(s) d x$ in the first interval 
and $\int_{x_{1}}^{x_{2}} f_{i}(x)(\theta(s) d x$ in the second interval, when the constant sanction $s$ was applied. The difference is hence $\int_{x_{0}}^{x_{1}} f_{i}(x)\left(\theta(s-\Delta s) d x-\int_{x_{0}}^{x_{1}} f_{i}(x)\left(\theta(s) d x+\int_{x_{1}}^{x_{2}} f_{i}(x)(\theta(s+\right.\right.$ $\Delta s) d x-\int_{x_{1}}^{x_{2}} f_{i}(x)\left(\theta(s) d x\right.$, which equals $(\theta(s-\Delta s)-\theta(s)) \int_{x_{0}}^{x_{1}} f_{i}(x) d x+(\theta(s+\Delta s)-$ $\theta(s)) \int_{x_{1}}^{x_{2}} f_{i}(x) d x$. When $\Delta s$ is small this converges to $-\theta^{\prime}(s) \Delta s \int_{x_{0}}^{x_{1}} f_{i}(x) d x+\theta^{\prime}(s) \Delta s \int_{x_{1}}^{x_{2}} f_{i}(x) d x$ which is negative when $\theta^{\prime}(s)>0$, since $\int_{x_{0}}^{x_{1}} f_{i}(x) d x>\int_{x_{1}}^{x_{2}} f_{i}(x) d x$. The latter inequality follows from the equality $\int_{x_{0}}^{x_{1}} f_{g}(x) d x=\int_{x_{1}}^{x_{2}} f_{g}(x) d x$, and from the fact that $f_{g} / f_{i}$ is increasing in $x$, in the same way as in the proof of the first proposition. $Q E D$.

\section{References}

[1] Andreoni,-James: 'Reasonable Doubt and the Optimal Magnitude of Fines: Should the Penalty Fit the Crime', Rand-Journal-of-Economics; 22(3), Autumn 1991, pages 385-95.

[2] Becker, Gary: 'Crime and Punishment: An Economic Approach', Journal of Political Economy, 1968, 76 (2).

[3] Lando, Henrik: 'Prevention of Crime and the Optimal Standard of Proof', Lefic Working Paper 2003-04, see http://web.cbs.dk/centres/lefic/workingpapers.html.

[4] Miceli, Thomas J: 'Optimal Criminal Procedure: Fairness and Deterrence', International-Review-of-Law-and-Economics; 11(1), May 1991, pages 3-10.

[5] Miceli, Thomas: 'Optimal Prosecution of Defendants Whose Guilt Is Uncertain' , Journal of Law, Economics and Organization; 6(1), Spring 1990, pages 189-202.

[6] : Polinsky, A. Mitchell and Shavell, Steven: 'The Fairness of Sanctions: Some Implications for Optimal Enforcement Policy', Working Paper, Harvard University, Olin Center, 12/98.

[7] Schauer F. and Zeckhauser R.: 'On the Degree of Confidence for Adverse Decisions', Journal of Legal Studies, vol XXV (January 1996). 
[8] Shavell, Steven: 'Economic Analysis of Accident Law', Harvard University Press, 1987. 